\title{
CORRECTION OF SCOLIOSIS DUE TO PARAPLEGIA SUSTAINED IN PAEDIATRIC AGE-GROUP
}

\author{
By G. M. Bedbrook, O.B.E., Hon.M.D.(W.A.), M.S.(Melb)., D.P.R.M., F.R.C.S., \\ F.R.A.C.S. \\ Royal Perth Rehabilitation Hospital, Shenton Park, Western Australia
}

Abstract. At the present time our preventive methods do not fully prevent the occurrence of scoliosis subsequent to juvenile paraplegia.

The methods of management must be: $(a)$ preventive; $(b)$ early non-operative correction, such as braces; and by (c) operative correction. The operative correction must be both an anterior and posterior procedure to give good spinal alignment.

Key words: Scoliosis; Correction; Paediatric age-group.

\section{The Problem}

ALL juveniles under the age of I I sustaining paralysis, partial or complete, above Tro will inevitably sustain scoliosis with a true lordo-scoliosis. The problem is well documented already in series published by Jackson (1975) and others. Our experience is similar except that the treatment has been undertaken in a highly sophisticated unit where urinary infection and stress problems such as decubiti have been largely eliminated and where the expertise to manage all aspects of management, respiratory, cardiac and urinary are readily available.

Pathologically the problem can only be solved by effectively creating a long bone in the spine with fusion over a long segment of the column usually $\mathrm{T}_{4}-\mathrm{L}_{5}$ and even involving the sacrum. The gross pathology is at the disc whilst factors such as muscle inequality, posture and pelvic obliquity are mitigating factors sometimes almost beyond recall when these young people present for management (Audic \& Maury, I968; Guttmann, I970; Odom \& Jackson, I974; O'Brien, Dwyer \& Hodgson, I975; Hensinger \& MacEwen, I976; Schwentker \& Gibson, I976) (Fig. I).

We must accept at present that we cannot fully prevent such a deformity but I hope that ere long its intensity will be such that fusion will not be required, for such operative procedures do limit mobility but are necessary when the scoliosis is more than 36 to $40^{\circ}$, after which, for many reasons, the curve becomes selfpropagating, causing difficulties to patients with pelvic obliquity, pressure sores, respiratory difficulties, abdominal discomfort and ultimately death. For this is a malignant process. Thus its management can be divided into a number of phases. Prevention, if possible; non-operative treatment by orthoses; operative technique; long-term follow-up and use of conservative methods-orthoses, posture.

\section{Prevention}

\section{Materials and Methods}

When a child starts to stand, it soon develops the normal lordosis of cervical and lumbar spine with the minor kyphos of the thoracic spine. The earliest care therefore is allowing the child to stand adequately in braces; to use a skate board and to be at rest in proper postural position. The methods exclude the use of a wheelchair altogether, for it can be replaced by the mobile stand-alone frame. 


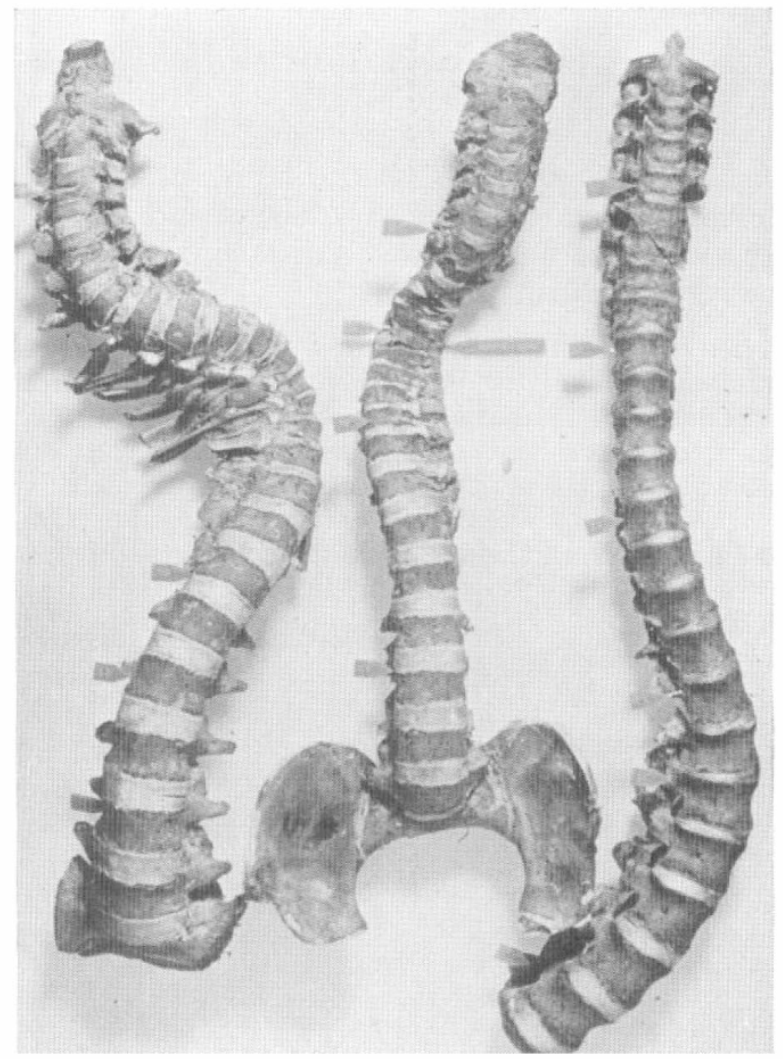

FIG. I

Left to Right: Idiopathic, congenital, paralytic.

Immediately one allows wheelchair mobility the occupant, even with orthoses, will bend to one side or the other and thus can cause and aggravate a scoliosis. Postural methods such as sport to aid maintenance of adequate spinal alignment should be introduced early for such children. Close supervision is required, particularly in cases with incomplete and unequal muscle power. Such children may need shoe raises to correct the developing pelvic obliquity. Recreational activity-long ignored in therapeutic care-had much to commend it. Sports such as javelin, discus, billiards and archery can assist in mobile care (Letts, Fulford \& Hobson, 1976).

\section{Early Care}

When the curve is progressive and over $40^{\circ}$ consideration to spinal exoskeleton braces is possible either of the Milwaukee type or Boston Bucket which allows more freedom. In such aparatus with supervision by careful therapists no sores will develop, mobility can certainly be maintained but not properly corrected and the curve may be slightly corrected. The uses of such apparatus mean its use for at least some years until spinal maturity is reached when, if the curve is still less than $35-40^{\circ}$ surgical correction can be deferred for a time anyway. Seven cases are at present being so managed. 


\section{Surgical Correction}

Thirteen cases have come to surgical correction. Severe fractures of the spine, particularly at lower dorsal levels, associated with complete spinal disruption and paraplegia may even in the adolescent (a young adult) result in severe scoliosis of a peculiar angular type associated with an increasing Kyphos rather than Lordosis. These cases are rare, but their recognition I believe is now possible. Early interference to 'fix' the spine is followed usually by disaster of great magnitude, as the following case illustrates.

F. Y., female, aet I8. Fracture dislocation Tio-Ti I with complete disruption and complete paraplegia was 'treated' by post-spinal plating which promptly cut out and became infected, necessitating their removal. Two years later her Kypho scoliosis was well developed and progressive. Her urinary tract was a balanced U.M.N. bladder with some infection. After a negative biopsy, anterior spinal fusion and partial correction by Dwyer's methods was achieved at which stage spinal osteomyelitis was proved. This was followed by a post-fusion and Harrington correction to a final result of $30^{\circ}$ (Figs $2 \mathrm{a}$ and 2b).

This case should correctly have been treated by postural reduction initially. If this had displaced, and I believe this would have occurred as proved in such cases in the series of Frankel (I968), Bedbrook and Edibam (I973), Leidholt (I969) and McSweeney (1973), then when the true instability and spinal curvature above $30^{\circ}$ became clear, definitive surgery would have been easier, more sure and would not have necessitated a life-long use of suppressive antibiotics.

For the II cases, fusion either posteriorly with an instrumentation or,

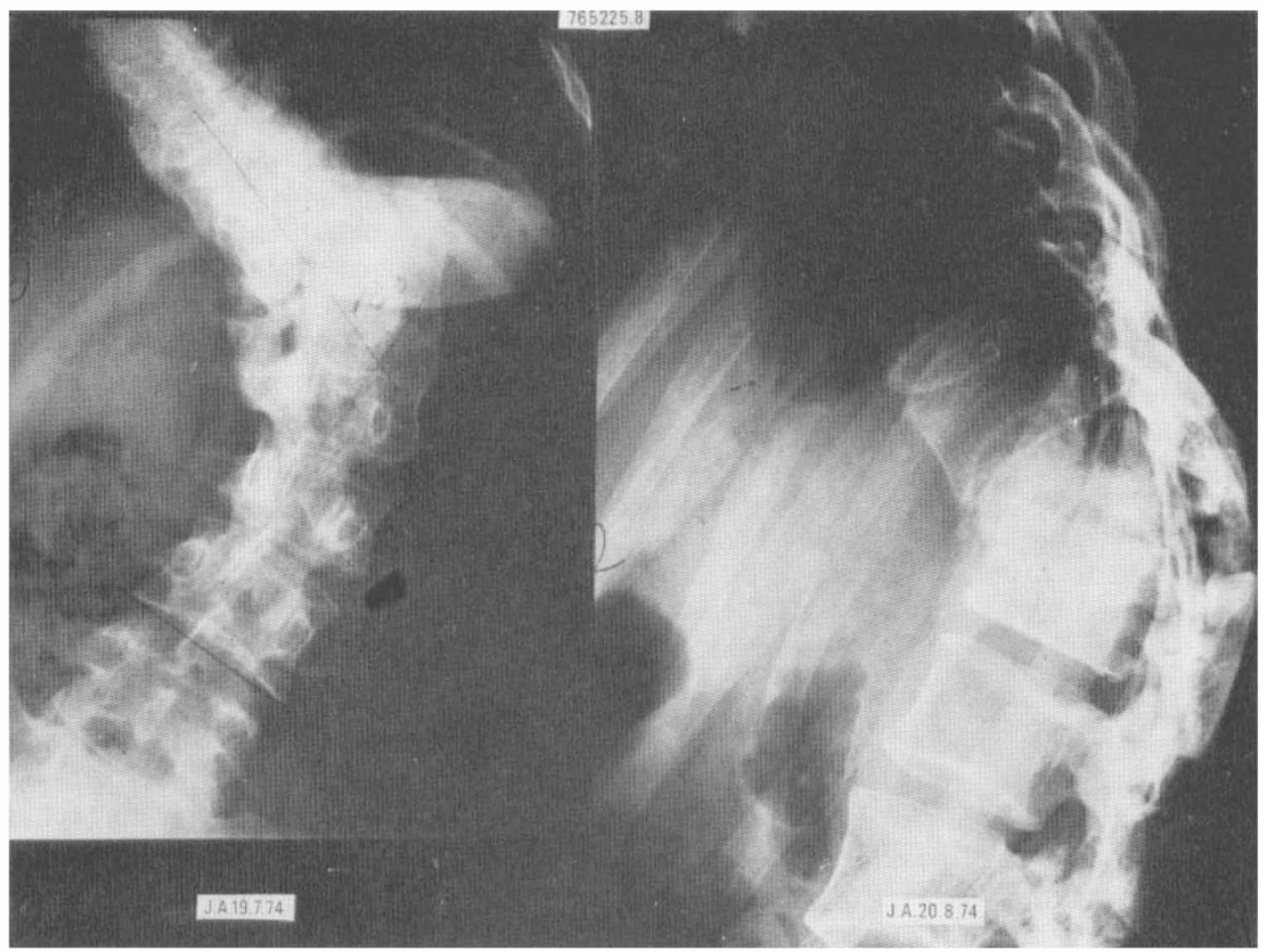

FIG. 2a 


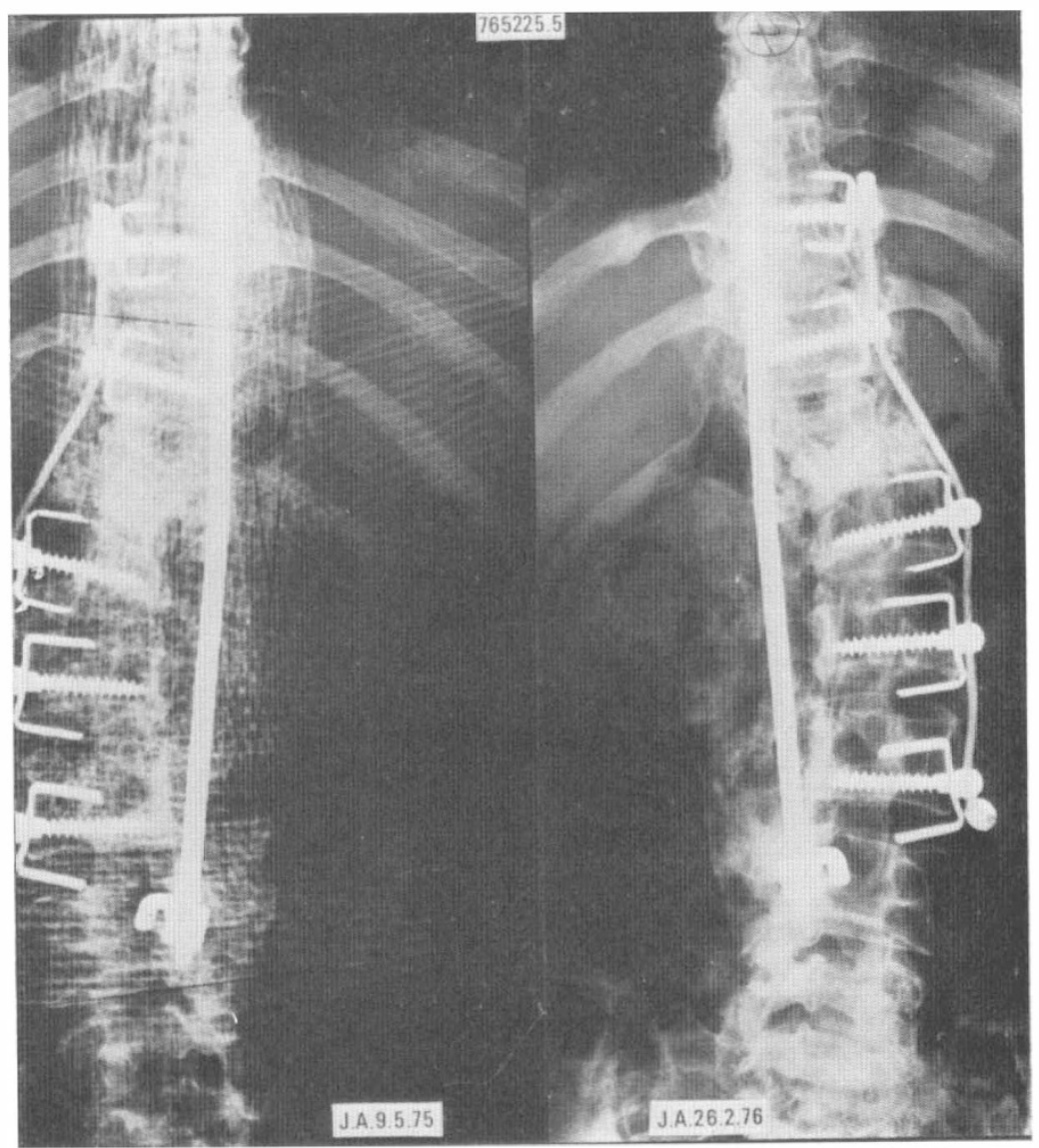

FIG. $2 b$

anteriorly with instrumentation is not sufficient to maintain correction in the face of extraordinary forces which beset the paraplegic spine and the extra mobility which by posture and inequality of muscle power cause even bone to deform greatly. Fusion anteriorly and posteriorly is mandatory.

Two case histories illustrate these points:

Female, aet 23. Paraplegia due to vascular cause aet II. Severe LD scoliosis originally corrected aet I7, by Dwyer himself, only to recur and need further correction anteriorly and posteriorly.

Male, aet I6. Paraplegia aet 8. At I4 Harrington posterior correction, I year in bed but correction poor. Had to have posterior graft removed and spine mobilised then an anterior procedure followed by a further posterior procedure (Figs $3 \mathrm{a}$ and $3 \mathrm{~b}$ ).

Such surgical techniques can only be undertaken in the precincts of a wellorganised spinal unit with its discipline of posture and urinary care, for although the techniques of surgery are possible the care of such patients is tedious and they need an intensive care attitude for months. Up to 12 months in bed may be needed although with the new materials available for polythene jackets earlier mobility is now possible with care- 6 months' bed rest followed by 6 months' jacket at least (Harrington, 1963). 

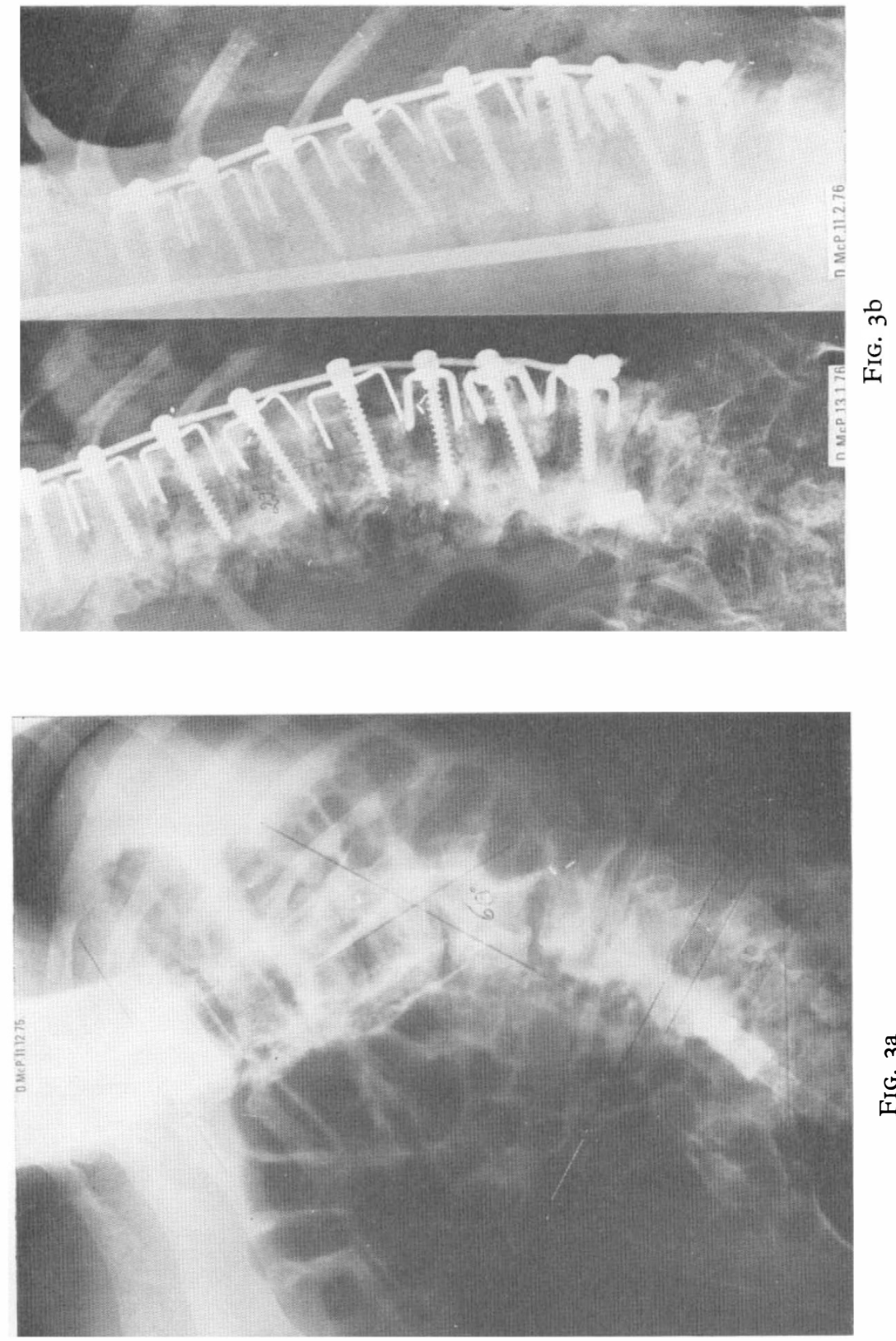

m

它 


\section{Results}

Recently Slinger (1975) reviewed our early results which showed the following: idiopathic and neurogenic ( 12 cases) shown in Table I and neurogenic (9 cases) shown in Table II.

\section{TABLE I}

\begin{tabular}{lcc}
\hline & Idiopathic & Neurogenic \\
\hline Number & I2 & 9 \\
Age (years) & 22 & 18 \\
Average correction & $67 \%$ & $57 \%$ \\
Average loss of correction & $14 \%$ & $7 \%$ \\
\hline
\end{tabular}

\section{TABLE II}

\begin{tabular}{lc}
\hline & Neurogenic \\
\hline Average correction (final) & $57 \%$ \\
Average loss correction & $14 \%$ \\
Severity of curve & $38^{\circ}-128^{\circ}$ \\
\hline
\end{tabular}

\section{SUMMARY}

At the present time our preventive methods do not fully prevent the occurrence of scoliosis subsequent to juvenile paraplegia.

The methods of management must be: $(a)$ preventive; (b) early non-operative correction, such as braces; and by $(c)$ operative correction. The operative correction must be both an anterior and posterior procedure to give good spinal alignment.

Further follow-up over many years will be necessary to watch these cases, but the initial results are satisfactory re correction. Function has been improved in both $(a)$ respiration and $(b)$ mobility, but at the 'expense' of reduction in some areas of recreation.

\section{ZUSAMMENFASSUNG}

Unsere preventiv Massnahmen verhindern nicht völlig die Entwicklung von Skoliose in jugendlicher Paraplegie. Die Methoden müssen sein $(a)$ preventiv, $(b)$ frühzeitig konservativ korrektiv, $(c)$ operativ korrektiv. Die operative Korrektion muss anterior und posterior erfolgen, um eine gute spinale Stabilisierung zu ermöglichen.

\section{REFERENCES}

Audic, B. \& MAURY, M. (1968). Secondary vertebral deformities in childhood and adolescence. International Medical Society of Paraplegia. Jerusalem. 6th Nov. 1968. Hadassah Medical Centre.

Bedbrook, G. M. \& EdibaM, R. C. (I973). The study of spinal deformity in traumatic spinal paralysis. Int $\mathcal{f}$. of Paraplegia, 10, 32 I-335 
FrANkel, H. L. (I968). The value of postural reduction in the initial management of closed injuries of the spine with paraplegia and tetraplegia, Part I. International Medical Society of Paraplegia. Jerusalem. 6th Nov. 1968. Hadassah Medical Centre.

GuttmanN, L. (1970). Spinal deformities in traumatic paraplegics and tetraplegics following surgical procedures. Int. F. of Paraplegia, 7,38 .

Harrington, P. R. (I963). Scoliosis in the growing spine. Pediatric Clinic of North America 10, 225-243.

Hensinger, R. N. \& MACEwen, G. D. (1976). Spinal deformity associated with heritable neurological conditions: Spinal muscular atrophy, Friedreich's ataxia, familial dysautonomia, and Charcot-Marie-tooth disease. F. Bone and foint Surg. 58A/r, 1 3-24.

JACKson, R. W. (1975). Surgical stabilisation of the spine. Int. F. of Paraplegia, 13, 7I-74.

LEIDHOLT, J. D. (I969). Evaluation of late spinal deformities with fracture dislocations of the dorsal and lumbar spine in paraplegics. F. of Paraplegia, 7, I6-27.

Letts, R. M., Fulford, R. \& Hobson, D. A. (I976). Mobility aids for the paraplegic child. F. of Bone and foint Surg. 58A/I, 38-4I.

McSwEENEY, T. (I973). Combined Symposium I.M.S.P. and VA Administration. Phoenix, Arizona.

O’Brien, J. P., Dwyer, A. P. \& Hodgson, A. R. (I975). Paralytic pelvic obliquity, its prognosis and management and the development of a technique for full correction of the deformity. F. of Bone and foint Surg. 57 A, 626-630.

Odom, J. \& JACKSON, R. W. (I974). Scoliosis in paraplegia. Int. F. of Paraplegia, II, 290292.

SChWENTKER, E. P. \& Gibson, D. A. (1976). The orthopaedic aspects of spinal muscular dystrophy. F. of Bone and foint Surg. 58A/1, 32-38.

SLINGER, B. S. (I975). Scoliosis-The results of operative correction with anterior spinal fusion and Dwyer instrumentation (from the Scoliosis Unit at the Royal Perth Rehabilitation Hospital). Rehabilitation Medical Conference, Perth, Western Australia. 